\title{
Utility of the laparoscopic approach to surgical treatment of acute appendicitis in a single surgical unit
}

\author{
Krzysztof Pragacz ${ }^{1}$, Marcin Barczyński², Rafał Kuchciński ${ }^{3}$ Andrzej Zieliński³, Ireneusz Nawrot ${ }^{4}$ \\ ${ }^{1}$ Department of General Surgery, Public Health Care Medical Centre, Staszow, Poland \\ ${ }^{2}$ Department of Endocrine Surgery, Third Chair of General Surgery, Jagiellonian University Medical College, Krakow, Poland \\ ${ }^{3}$ Department of General Surgery, St Alexander Hospital, Kielce, Poland \\ ${ }^{4}$ Chair and Department of General, Vascular and Transplantation Surgery, Medical University of Warsaw, Poland
}

Videosurgery Miniinv 2014; 9 (2): 234-238

DOI: $10.5114 /$ wiitm.2014.42511

\begin{abstract}
Introduction: Acute appendicitis $(A A)$ is one of the most common reasons for emergency surgery within the abdominal cavity in Poland.

Aim: To compare outcomes of surgical treatment of AA using both classical (OA) and laparoscopic methods (LA).

Material and methods: Retrospective analysis of 299 patients (157 men and 142 women) operated on in 2008-2011 due to $A A$. The following comparisons between $L A$ and $O A$ were done: mean operative time, mean hospital stay after surgery, conversion rate, proportion of $L A$ to $O A$ in successive years.

Results: Laparoscopic appendectomy was performed in 170 (56.9\%) patients (74 men and 96 women), whereas $O A$ was done in 89 (29.8\%) patients (44 men and 45 women). In 13.4\% of patients (24 men and 16 women) conversion from $L A$ to $O A$ was done. Mean operating time was $53.4 \pm 16.1 \mathrm{~min}$ (range: $25-100 \mathrm{~min}$ ) for $L A$, and 55.4 $\pm 20.2 \mathrm{~min}$ (range: $20-140 \mathrm{~min}$ ) for $O A ; p=0.64$. Mean hospital stay after $L A$ was $4.0 \pm 1.2$ days (range: $2-9$ days), while it was $6.0 \pm 4.2$ days (range: 2-28 days) after $O A ; p<0.001$. Laparoscopic appendectomy was $24.1 \%$ of all appendectomies performed in the year 2008, 54.1\% in the year 2009, and in consecutive years $71.7 \%$ in 2010 and $65.6 \%$ in 2011.

Conclusions: Laparoscopic appendectomy method did not require longer surgery times and entailed shorter hospital stays as compared with OA. In our opinion, LA should be the preferred approach in surgical treatment of AA in adults.
\end{abstract}

Key words: acute appendicitis, open appendectomy, laparoscopic appendectomy.

\section{Introduction}

Acute appendicitis (AA) is one of the most common reasons for emergency surgery within the abdominal cavity carried out in Poland [1, 2]. For decades, appendectomy through classic laparotomy (OA - open appendectomy) was considered the gold standard in AA treatment. The introduction of laparoscopy opened new surgical opportunities and minimally invasive techniques have become methods of choice in the surgical treatment of many pathologies [1, 3]. Additionally, a trend can be seen in the surgical treatment of AA whereby the laparoscopic method (LA - laparoscopic appendectomy) is used more frequently [3-7]. The potential benefits of using the laparoscopic technique in AA treatment are the subject of numerous studies, while the published data are not always consistent [8]. In our own surgical unit, we started to perform LA in 2008. 


\section{Aim}

The aim of this study was to compare outcomes of surgical treatment of AA using both classical and laparoscopic methods.

\section{Material and methods}

The retrospective analysis included data on $314 \mathrm{pa}-$ tients operated on at the Department of General Surgery in 2008-2011 due to AA. Fifteen patients with incomplete data were withdrawn from further analysis. The final assessment included data on 299 patients (157 females and 142 males) aged 18-90. The following comparisons between LA and OA were done: mean operative time, mean hospital stay after surgery, conversion rate, and the LA-OA surgery trend in individual years from 2008 to 2011.

\section{Surgical technique}

The laparoscopic operations were performed using three trocars. The pneumoperitoneum was created with a Veress needle introduced below or above the navel and then a $10 \mathrm{~mm}$ optical trocar was inserted in the same place. Another $10 \mathrm{~mm}$ trocar was placed in the area above the pubic symphysis. The third, $5 \mathrm{~mm}$, trocar was inserted in the left iliac fossa (in the first year of LA application) or above the caecum (from the second year of LA application). The appendicular mesentery was ligated in various ways: most frequently a harmonic scalpel was used, less often a BiClamp, and sporadically vascular clips. The appendicular base was most frequently ligated using plastic clips (Hem-o-lok), less frequently double ligature. No invagination of the appendicular stump was performed.

When the classic method was used, the surgery was most frequently performed by a lower right pararectus incision, with Mc Burney's incision used less frequently. As to the conversion from the lapa-

Table I. General characteristics of the study group

\begin{tabular}{|lcc|}
\hline Parameter & $\begin{array}{c}\text { Laparoscopic } \\
\text { appendectomy }\end{array}$ & $\begin{array}{c}\text { Open } \\
\text { appendectomy }\end{array}$ \\
\hline Number of patients & 170 & 89 \\
\hline Males (\%) & 44 & 49 \\
\hline Females (\%) & 56 & 51 \\
\hline Mean age [years] & $31.9 \pm 12.9$ & $41.8 \pm 17.7$ \\
\hline
\end{tabular}

roscopic to the classic method, the most common option was a lower median incision.

\section{Results}

Laparoscopic appendectomy was performed on 170 (56.9\%) patients (74 males and 96 females) and OA on $89(29.8 \%)$ patients (44 males and 45 females). In $13.4 \%$ of patients (24 males and $16 \mathrm{fe-}$ males) conversion from LA to OA was done. Table I contains the demographic characteristics of the population covered by this study.

In 2008, the number of LA operations accounted for $24.1 \%$ of all appendectomies. In the consecutive years the percentage of LA increased to $71.7 \%$ in 2010 and $65.6 \%$ in 2011 (Figure 1).

The mean operating time was $53.4 \pm 16.1 \mathrm{~min}$ (range: $25-100 \mathrm{~min}$ ) for $\mathrm{LA}$ and $55.4 \pm 20.2 \mathrm{~min}$ (range: $20-140 \mathrm{~min}$ ) for $\mathrm{OA} ; p=0.64$ (Figure 2). The mean hospital stay after LA lasted $4.0 \pm 1.2$ days (range: 2-9 days), and after the OA $6 \pm 4.2$ days (range: $2-28$ days); $p<0.001$ (Figure 3).

In the study presented, $13.4 \%(40 / 299)$ of the operations required a conversion of the laparoscopic method to the classical one. The mean operating time with a conversion was $91.1 \pm 19.5$ min (range: 55-120 min). On average, the patients who underwent the OA to LA conversion surgery stayed in the hospital for $7.4 \pm 3.9$ days (range: $3-25$ days). The conversion was most frequently necessitated by complicated appendicitis in the form of a periappendicular infiltration or abscess, or its perforation with high volumes of pus and fibrin in the peritoneal cavity,

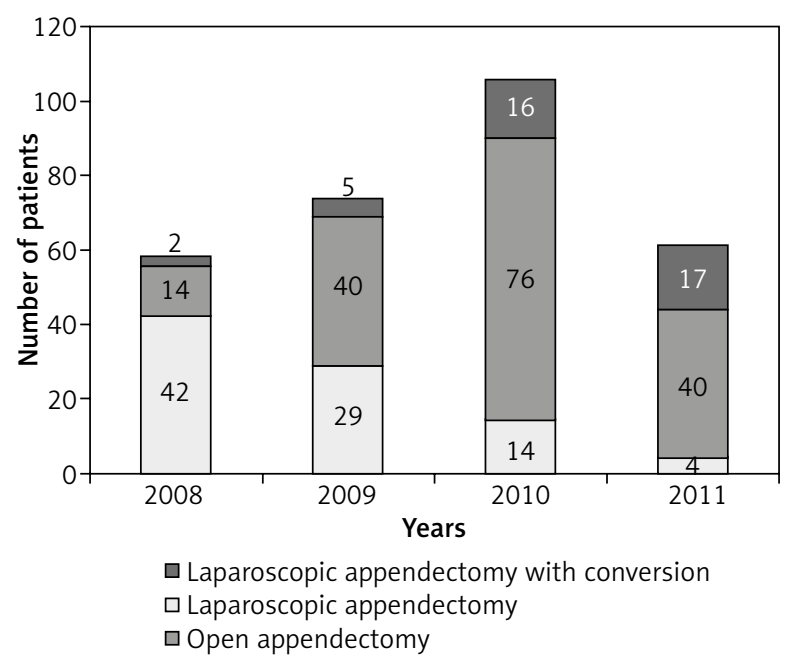

Figure 1. Number of patients operated between the years 2008 and 2011 


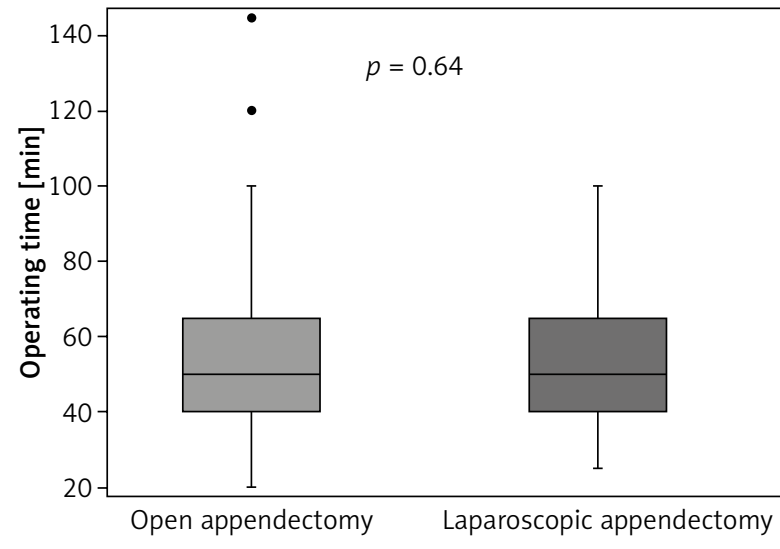

Figure 2. Distribution of operating time in respective groups of patients: undergoing open versus laparoscopic appendectomy

then the retrocaecal appendix and intestinal adhesions in the caecum area. Rare grounds for the conversion were such pathologies as sigmoid tumour, omentum necrosis, acute pancreatitis and ovarian cyst torsion diagnosed during the surgery. Detailed reasons for conversion are presented in Table II.

In the studied material no perioperative mortality was reported, and neither were complica-

Table II. Reasons for conversion from laparoscopic to open appendectomy

\begin{tabular}{|lc|}
\hline Reasons for conversion of laparoscopic surgery & $\begin{array}{c}\text { Number } \\
\text { of cases }\end{array}$ \\
\hline $\begin{array}{l}\text { Periappendicular infiltration or abscess, } \\
\text { appendix perforation with high volumes } \\
\text { of pus and fibrin in the peritoneal cavity }\end{array}$ & 20 \\
\hline Retrocaecal appendix & 5 \\
\hline Intestinal adhesions in the caecal area & 5 \\
\hline $\begin{array}{l}\text { Iatrogenic caecal perforation during appendix } \\
\text { preparation }\end{array}$ & 1 \\
\hline $\begin{array}{l}\text { Massive bleeding not to be contained } \\
\text { in laparoscopic technique }\end{array}$ & 1 \\
\hline Sigmoid tumour & 2 \\
\hline Omentum necrosis & 1 \\
\hline Acute pancreatitis & 1 \\
\hline Ovarian cyst torsion & 1 \\
\hline $\begin{array}{l}\text { Major intestinal flatulence following oesopha- } \\
\text { geal intubation }\end{array}$ & 1 \\
\hline $\begin{array}{l}\text { Failure of laparoscopy equipment during } \\
\text { the surgery }\end{array}$ & \\
\hline
\end{tabular}

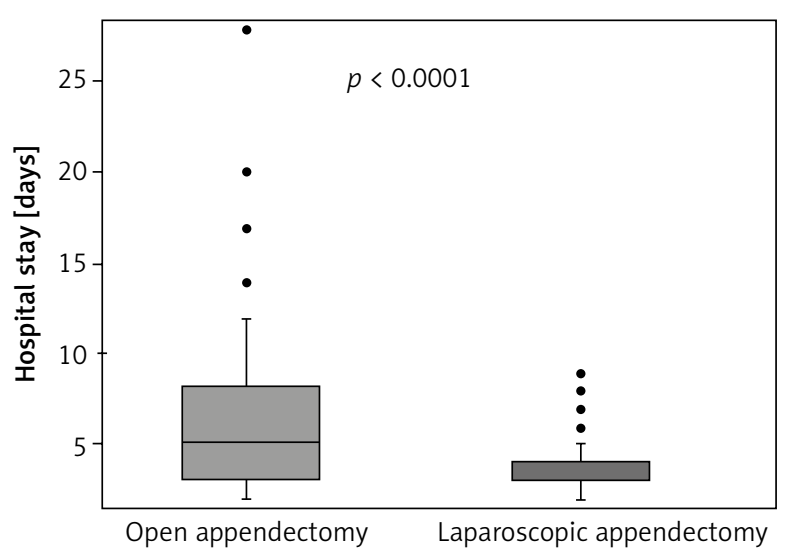

Figure 3. Distribution of hospital stay in respective groups of subjects: undergoing open versus laparoscopic appendectomy

tions which would require another surgical intervention.

\section{Discussion}

Acute appendicitis is a common pathology, particularly in the white race. Appendectomy by classic laparotomy was performed for the first time by Mc Burney in 1894, while in 1980 the German gynaecologist Semm was the first to perform laparoscopic appendectomy to treat $\mathrm{AA}$ [3].

In recent years, most surgeons, possibly inspired by the outstanding results produced by laparoscopic cholecystectomy, have been keener to perform LA more frequently than $\mathrm{OA}[1]$. In the literature some potential benefits of LA are given, such as shorter hospital stays, better cosmetic effect, less intense postoperative pain, lower percentage of infections in the operated site as well as faster return to normal diet and daily activity [5, 6, 8-14].

As for the time needed for hospital stay after LA, the available data are inconsistent. Our study, like those by other authors, has shown statistically significant shorter hospital stays after LA when compared with $\mathrm{OA}[5,6,8,13,15,16]$. Yet some other researchers have not observed statistically significant differences between LA and OA in that regard [7, 12, 17, 18]. Some researchers suggest that the differences in hospitalisation duration may result from the healthcare system rather than the medical differences between the two procedures in question [18].

There is currently much controversy as to the duration of LA and OA surgery. Some researchers have 
found statistically significant differences, and associated the longer time with such aspects as gas insufflation, trocar insertion and diagnostic laparoscopy $[7,8,11,15,17,19]$. That opinion is not supported by the findings presented here as well as studies by other authors where no statistically significant differences as to the duration of the surgery in question were found $[13,18,20]$. The literature available to us contained no mention of surgery where the LA performance time was shorter than in the case of OA. The operations analysed in our study were performed not only by specialist general surgeons but also resident physicians sufficiently experienced in minimally invasive surgery, assisted and supervised by a general surgery specialist.

In the study presented here, the conversion percentage was $13.4 \%$ and in 5 cases it was related to the diagnosis of another pathology within the abdominal cavity. It is estimated that the number of preoperative misdiagnoses amounts to $10-30 \%$ [1, $2,14]$. According to the literature, such a high figure may result from the fact that a mere $50-60 \%$ of the patients present classic clinical AA symptoms, and in women pathologies in the pelvis minor are a frequent source of diagnostic errors [1]. The development of diagnostics tests such as ultrasound, computed tomography (CT) and magnetic resonance imaging (MRI) has contributed to not exactly the confirmation of AA diagnosis but rather to finding other pathologies in the abdominal cavity which have similar clinical symptoms. In clinically atypical patients it seems justified to consider diagnostic laparoscopy early on as it is readily available and complications are infrequent $[1,10,15]$. This is one of the key aspects pointing to the advantages of LA over OA.

Apart from benefits, each new procedure should be characterised by its safety such as lower incidence of complications. In the study presented here, no fatal cases were reported, a fact compatible with most previous publications where the percentage of fatal complications for LA and OA was $0.05 \%$ and $0.3 \%$, respectively [9]. In most studies, the general ratio of postoperative complications after LA was statistically significantly lower than after OA [6, 7, $9,13]$. Only the incidence of intra-abdominal abscesses was reported to be more frequent after LA than OA $[4,8,19,21]$, which may be due to the fact that $\mathrm{CO}_{2}$ insufflation in LA is conducive to the dissemination of bacteria in the abdomen, particularly in perforated AA [10]. In the study presented here, no patient sustained an intra-abdominal abscess as a result of the surgery, which supports our algorithm where a conversion to OA is performed in cases of a periappendicular infiltration or abscess, and perforation of the appendix with high volumes of pus and fibrin in the peritoneal cavity.

\section{Conclusions}

The LA method did not require longer surgery times and entailed shorter hospital stays as compared with OA. In our opinion, LA should be the preferred approach in surgical treatment of AA in adults.

\section{References}

1. Strzałka M, Bobrzyński A. Laparoscopy in the treatment of acute abdominal disease. Videosurgery Miniinv 2008; 3: 1-9.

2. Anielski R, Barczyński M, Cichoń S, et al. Acute appendicitis in Cracow population. Przegl Lek 2001; 58: 1034-7.

3. Litynski GS. Kurt Semm and the fight against skepticism: endoscopic hemostasis, laparoscopic appendectomy, and Semm's impact on the "laparoscopic revolution". JSLS 1998; 2: 309-13.

4. Kiudelis M, Ignatavicius P, Zviniene K, et al. Analysis of intracorporeal knotting with invaginating suture versus endoloops in appendiceal stump closure. Videosurgery Miniinv 2013; 8: 69-73.

5. Kenig J, Richter P. The need for culture swabs in laparoscopically treated appendicitis. The need for culture swabs in laparoscopically treated appendicitis. Videosurgery Miniinv 2013; 8: 310-4.

6. Strzałka M, Bobrzyński A, Budzyński A, et al. Open or laparoscopic appendectomy? Videosurgery Miniinv 2009; 4: 110-4.

7. Katkhouda N, Mason RJ, Towfigh S, et al. Laparoscopic versus open appendectomy: a prospective randomized double-blind study. Ann Surg 2005; 242: 439-48.

8. Sauerland S, Jaschinski T, Neugebauer EA. Laparoscopic versus open surgery for suspected appendicitis. Cochrane Database Syst Rev 2010; 6: CD001546.

9. Guller U, Hervey S, Purves H, et al. Laparoscopic versus open appendectomy outcomes comparison based on a large administrative database. Ann Surg 2004; 239: 43-52.

10. Memon MA. Laparoscopic appendicectomy: current status. Ann R Coll Surg Engl 1997; 79: 393-402.

11. Frazee RC, Roberts JW, Symmonds RE, et al. A prospective randomized trial comparing open versus laparoscopic appendectomy. Ann Surg 1994; 219: 725-8.

12. Milewczyk M, Michalik M, Ciesielski M. A prospective, randomized, unicenter study comparing laparoscopic and open treatments of acute appendicitis. Surg Endosc 2003; 17: 1023-8.

13. Wei HB, Huang JL, Zheng ZH, et al. Laparoscopic versus open appendectomy: a prospective randomized comparison. Surg Endosc 2010; 24: 266-9.

14. Apelgren KN, Molnar RG, Kisala JM. Laparoscopic is not better than open appendectomy. Am Surg 1995; 61: 240-3.

15. Yong JL, Law WL, Lo CY, et al. A comparative study of routine laparoscopic versus open appendectomy. JSLS 2006; 10: 188-92. 
16. Yaghoubian A, Kaji AH, Lee SL. Laparoscopic versus open appendectomy: outcomes analysis. Am Surg 2012; 78: 1083-6.

17. Minné L, Varner D, Burnell A, et al. Laparoscopic vs open appendectomy. Prospective randomized study of outcomes. Arch Surg 1997; 132: 708-11.

18. Peiser JG, Greenberg D. Laparoscopic versus open appendectomy: results of a retrospective comparison in an Israeli Hospital. Isr Med Assoc J 2002; 4: 91-4.

19. Swank HA, Eshuis EJ, van Berge Henegouwen MI, et al. A shortand long-term results of open versus laparoscopic appendectomy. World J Surg 2011; 35: 1221-6.

20. Vettoretto N, Montori G, Bartoli M, et al. Lesson learned from 10 years' experience in laparoscopic appendectomy in a community hospital. Updates Surg 2012; 64: 285-8.

21. Bregendahl S, Nørgaard M, Lauberg S, et al. Risk of complications and 30-day mortality after laparoscopic and open appendectomy in a Danish region, 1998-2007: a population-based study of 18426 patients. Pol Przegl Chir 2013; 85: 395-400.

Received: 2.12.2013, accepted: 26.01.2014. 